us all. In the first 50 pages he describes the life and works of this remarkable physician and gives the background to the Sedleian Professorship. The lectures themselves are contained within the next 100 pages, in which Dewhurst's original translations are amplified by copious footnotes. These lectures, which are a delight to read, formed the basis of many of Willis's subsequent books, which exerted such a profound impact on the development of neurological psychiatry. The volume is beautifully produced and will give endless pleasure. A must for all neurological libraries and an excellent present for the neurological tyro.

CD MARSDEN

Organic Psychiatry By William Alwyn Lishman (pp 967; £14.50) Oxford: Blackwell Scientific Publications, 1980. This reprinted edition of Alwyn Lishman's encyclopaedic book, first published in 1978, will be welcomed by those unfortunate people who were unable to afford the high price of the first edition and can now purchase this paperback print at a more reasonable cost. That is not to say that the first edition was not worth every penny of the price, only that books such as this command such a large audience, and that high prices preclude many who would perhaps make the most use of them, for example students, from owning them. This soft-back version, with nearly 900 pages of well-reviewed literature on organic psychiatry, is a bargain that those interested will find hard to refuse.

Apart from the clearing up of some minor spelling mistakes, the printing is as the first edition, in which Professor Lishman examines psychiatric symptomatology associated with various organic disorders, especially those of the central nervous system. Part 1 is devoted to clinical assessment and differential diagnosis of psychopathology with special reference to the detection of organic brain syndromes, and discussion of clinical presentations arising either from generalised organic brain disease, or those which have regional affiliations based on localised pathology.

The second part is devoted to specific disorders covering, in addition to such neuropsychiatric topics as head injury, epilepsy and cerebrovascular accidents, the psychopathology associated with endocrine diseases, metabolic disorders, vitamin deficiencies and toxic disorders. Of all these chapters, those on head injury, and dementia, stand out for their particularly well-reviewed and clear presentation of the available information in these fields. Available, that is, until the mid-1970s when, presumably the writing of the book was complete. The fact that in the late $70 \mathrm{~s}$ and early 1980s some interesting new advancements in several of the fields discussed by Professor Lishman have occurred, and of course are not included in this book, in no way reflects on the quality of that produced, merely that the field of organic psychiatry is progressing rapidly. The role of neurotransmitters generally in the pathogenesis of psychiatric symptoms is poorly covered, monoamines for example not being mentioned in the index.

The really great virtue of this book is its readability. There are few texts of this size that can be read from cover to cover, but the easy style and lively presentation of data that Professor Lishman has produced make its digestion comfortable.

\section{MICHAEL TRIMBLE}

Childhood Neurological Problems: A Textbook for Health Care Professionals By Doris A Trauner (pp 150; £15.25) London: Year Book Med Pub, 1980. Dr Trauner, an Assistant Professor of Neurology and Pediatrics, has subtitled her book "A Textbook for Health Care Professionals," with a broad spectrum of readers in mind among nurses, physiotherapists, "speech pathologists" and anyone who deals with children with problems involving the nervous system. I would agree with Dr Nyhan who, in a foreword, expresses the belief that it will also be useful to physicians in family practice and paediatrics. Some of the chapters could be read with benefit also by teachers, whose fears of epilepsy, cerebral palsy and other neurological problems stem largely from ignorance. To write a successful book for this readership is not easy with the risks of brevity and oversimplication producing a misleading picture of complex disorders, but this has been skilfully avoided with emphasis on principles and brief but generally adequate details of specific disorders. The first two chapters, on "Normal Neurologic Development" and "The Neurologic Examination" set the scene and serve as an introduction to the following twelve chapters devoted to particular categories of disorder. I wish that the importance of accurate and regular measurement and recording of the head circumference had been stressed more strongly, since this is a vital statistic all too of ten neglected. The book is written basically for an American non-medical readership, but there are few changes needed for readers on this side of the Atlantic. Hyperactivity syndromes and learning disabilities, which occupy a higher proportion of the time of Paediatric Neurologists and Paediatricians in North America than in Britain, are dealt with in a pragmatic and helpful way. Belief in the need for a neurological opinion "to rule out neurological problems" in children with learning disorders is correctly regarded as a misleading concept widely held in educational circles. The value of routine electroencephalography in children with learning disabilities also receives-deservedly-short shrift.

I hope this book will be widely read by those at whom it is aimed and, if it is dipped into by some of their medical 8 colleagues for whom the subject is terra웅 incognita, so much the better.

FM BRETT

Persistent Pain, Vol II Edited by Sampson Lipton (pp 398; \$49.50) London: Academic Press Inc 1980.

This is the second volume to be issued under the above title, the first having been published in 1977. In both volumes chapters are contributed by experts in various fields. In Volume 1 , the range offered covered many of the techniques which are used in treatment in Pain Clinics, and outlined the anatomy and physiology of pain. This was excellent, and still provides a valuable source for reference. In Volume II, some subjects such as acupuncture have been repeated, and others, such as dental, oral and facial pain, have been expanded. The appearance of a subject in Volume I does not, therefore, exclude it from Volume II. However, the process is not entirely one of updating and, unfortunately, some new chapters have not been written entirely from the 